stigma they are trying to remove. The report unfortunately sidetracks the controversial issue of the driving licence. Again, the expert teams and the special centres are important conceptions, but where is the finance to establish, maintain, and staff these centres when the whole hospital service is crying out for more money to keep in existence? Like its predecessors this committee has posed more questions than it answers. Even so, if most of its recommendations were to be met about 33,000 people developing epilepsy each year would have a better chance of accurate diagnosis, effective therapy, and of finding an acceptable place in the community.

\section{Drug Problems}

A third of the schools in the U.S.A. have a serious drug problem; and over 300 children died last year in New York alone from heroin addiction. ${ }^{1}$ Those who believe that it couldn't happen here should look at the situation ${ }^{2}$ in Sweden, where drug addiction has become much more serious recently and is showing signs of following the American pattern.

The Home Office does not, then, need any justification for its argument that the Misuse of Drugs Bill ${ }^{3}$ is urgently needed; and this urgency probably accounts for the appearance of the report ${ }^{4}$ by the Advisory Committee on Drug Dependence on which the legislation is based two weeks after the publication of the Bill itself.

The report gives an objective account of the use and abuse of amphetamine and lysergic acid diethylamide, and acknowledges the help of the B.M.A. in its preparation. ${ }^{5}$ The advisory committee was clearly concerned with the preventive role that the schools can play - and it is reassuring that the Health Education Council is examining methods by which teenagers can be warned of the dangers of drug-taking without the propaganda having the wrong effect. R. S. P. Wiener has, indeed, argued ${ }^{6}$ that warnings may be ignored by those already on drugs and put ideas into the heads of the others. But no one would disagree with the committee's view that schools meeting with addiction among pupils should have specialist advice available to help them. The committee supported the recommendation of the Plowden Council ${ }^{7}$ that teachers should be appointed to special posts to establish closer links between schools and local medical and welfare services. Another reasonable recommendation is that local authorities should set up advice centres to which drug users and parents could go for reliable information.

The major recommendations of the report have been incorporated into the Misuse of Drugs Bill, but the outstanding exception is the Committee's proposal that "the powers of the General Medical Council should be extended to enable it to deal with reckless over-prescribing." Comment in these columns ${ }^{8}$ on the Bill has already regretted that the functions and powers of the G.M.C. could not have been revised in this way. On this issue many doctors will agree with the statement made by the committee that "the body already concerned with professional standards is a more appropriate one to deal with over-prescribing than a specially constituted tribunal."

1 The Times, 13 March 1970.

2 Newsweck, 23 March 1970.

3 Misuse of Drugs Bill, 1970. London, H.M.S.O., 1970.

4 Advisory Committee on Drug Dependence, The Amphetamines and Lysergic Acid Diethylamide (LSD). London, H.M.S.O., 1970. 6s. Od

- The report of the Committee on Medical Science, Education, and Research's Working Party on Control of Amphetamine Preparations is available from the B.M.A. on request.

- Wiener, R. S. P., Drugs and Schoolchildren. London, Longman, 1970.

7 Central Advisory Council for Education (England), Children and their Primary Schools. London, H.M.S.O., 1966.

8 British Medical fournal, 1970, 1, 705.

\section{Feeding Difficulties}

Family doctors are from time to time faced with the problem of the worried mother whose infant has feeding difficulties Some babies appear to be normal; others have obvious abnormalities. A history and physical examination may not provide the diagnosis, and the doctor will be frustrated in his search for information because of the scanty references to "dysphagia" in many textbooks. Of particular value therefore is a recent review of the subject by $R$. S. Illingworth, ${ }^{1}$ who suggests a simple classification of the causes and offers helpful comments on diagnosis and prognosis.

The causes may be considered in three main groups: gross congenital malformations, neuromuscular disorders, and acute infections. It is in the second group that most of the diagnostic and prognostic difficulties are encountered.

Many of the congenital deformities will be evident on examination of the infants at birth-for example, cleft palate, macroglossia, or micrognathia. Others produce characteristic signs within a few hours of birth-choanal atresia and tracheooesophageal fistula, for example. A bifid uvula in an infant with nasal regurgitation would suggest the possibility of a submucous palatal cleft. Though this cannot be seen, there will be a V-shaped midline notch at the posterior border of the hard palate, evident on palpation. Feeding difficulties associated with laryngeal stridor may result from congenital anomalies of the great vessels when the oesophagus and trachea are compressed between the aorta and the ductus (in the case of a right-sided aortic arch) or between the two sides of a double aortic arch. The treatment and prognosis are in the hands of specialist surgeons.

The neuromuscular disorders are less clearly defined, more difficult to diagnose, sometimes less responsive to treatment, and often unpredictable in their outcome. The commoner ones include delayed maturation, cerebral palsy (spastic or athetoid), cranial-nerve abnormalities, bulbar and suprabulbar palsy, Möbius's syndrome (congenital facial diplegia with ocular palsies), and rumination. Delayed maturation is to be expected in small premature babies and those who are mentally retarded. But it may be due to "dissociation in development," a term introduced by Illingworth ${ }^{2}$ in 1958 to describe an important normal variation in the development of many systems, including auditory, visual, motor systems, reading ability, and sphincter control, any one or more of which may be advanced or retarded. It is reasonable to suppose that such a complicated process as swallowing might also be included. In such cases dysphagia will disappear when maturation is finally achieved. An infant suffering from cerebral palsy may have a combination of prematurity, mental subnormality, spasticity, muscular inco-ordination, and cortical defects, all contributing to dysphagia: the prognosis is less in doubt here. Infants with bulbar or suprabulbar palsy may recover in a matter of weeks or not for some years. Illingworth comments that when the facial nerves are involved in infants with dysphagia there is a tendency to consider them as examples of Möbius's syndrome, but he adds that it is uncertain whether this syndrome is an entity. Rumination is included as an odd form of swallowing difficulty; it is probably a psychosomatic condition.

The acute infections include tetanus neonatorum (in which dysphagia is often the first sign), diphtheria, poliomyelitis, stomatitis, and oesophagitis.

There are three particular difficulties in attempting a

1 Illingworth, R. S., Archives of Disease in Childhood, 1969, 44, 655. Illingworth, R. S., Archives of Disease in Childhood, 1958, 33, 118. 
prognosis in infantile dysphagia. The first is the frequency of associated mental retardation, especially in those infants with congenital abnormalities. Illingworth stresses the importance of careful developmental assessment in every case. The second difficulty is concerned with what he has described as the "sensitive" or critical period. ${ }^{3}$ He pointed out that if babies are not given solid food-as distinct from thickened feedswhen they have recently learned to chew (average age 6-7 months) they will refuse or vomit solids later. If a baby with dysphagia is not given solid foods at the sensitive period, but is given them subsequently, the vomiting or refusal may be mistaken for the primary condition when in fact it is due to his having passed the critical period without being offered solids.

The third problem is the pseudoretardation from which infants and young children with dysphagia of more than a few weeks may suffer as a result of admission to hospital and separation from their mothers. This may lead to a wrong diagnosis of mental retardation in a mentally normal child. Even if the condition is recognized, it is difficult to foretell how much of the retardation will be reversible after the child returns home.

In summing up his own series of nineteen cases Illingworth writes that he was struck with the low mean intelligence quotient of the neuromuscular group, but that the most notable feature of their follow-up examination was the remarkable improvement many of them showed, with complete recovery at school age in those who had the most severe disabilities in infancy, even in those who had to be tube-fed for several months.

\section{Antilymphocyte Serum and Glomerulonephritis}

Antilymphocyte serum or relatively pure antibody globulin fractions prepared from this serum can suppress immunity reactions, thus prolonging the survival of both skin and organ grafts. ${ }^{1}$ The action of the antibody globulin fractions is still far from completely understood, but it includes a toxic effect on lymphocytes, and these fractions certainly inhibit cellmediated immune responses more powerfully than they do the production of circulating antibody. ${ }^{2}$

The use of antibody globulin fractions (A.L.G.) in the treatment of glomerulonephritis thought to be initiated or rendered chronic by immune mechanisms might seem attractive, but it has not been reported for a variety of reasons. Evidence has been lacking that cell-mediated immune

1 British Medical fournal, 1968, 2, 507.

2 James, K., Clinical and Experimental Immunology, 1967, 2, 615.

Dixon, F. J., Feldman, J. D., and Vazquez, J. J., fournal of Experimental Medicine, 1961, 113, 899.

4 Gray, J. G., Monaco, A. P., Wood, M. L., and Russell, P. S., fournal of Immunology, 1966, 96, 217.

5 Jeejeebhoy, H. F., and Vela-Martinez, J. M., Transplantation, 1968, 6, 149.

7 Iwasaki, Y., et al., Surgery, Gynecology and Obstetrics, 1967, 124, 1. Deodhar, S. D., Kuklinca, A. G., Vidt, D, G., Robertson, A. L., and Hazard, J. B., New England fournal of Medicine, 1969, 280, 1104. Penn, I., Hammon, W., Brettschneider, L., and Starzl, T. E.,

9 Berlyne, G. M., and Baker, S. B. de C., Quarterly fournal of Medicine, 1964, 33, 105.

10 Sharpstone, P., Ogg, C. S., and Cameron, J. S., British Medical White, R. H R , 533 .

Fournal, 1966, 2, 853 .

fournal, 1966, 2, 853. Pirofsky, B., Bardana, E. J., jun., Bayracki, C., and Porter, G. A., 13 Lerner, of the American Medical Association, 1969, 210, 1059, Lerner, R. A., Glassock, R. J., and Dixon, F. J., fournal of Experimental Medicine, 1967, 126, 989.

14 Lewis, E., Rocklin, R. E., and David, J. R., presented at the meeting of the European Society for Paediatric Nephrology, Helsinki, June 1969. mechanisms play a part in glomerulonephritis in man. Doubts have also been felt about the use of antibody globulin fractions when alternative treatments might be available. For the antibody globulin is itself a foreign protein able to produce a serum-sickness type of nephritis $;^{3}$ it has side-effects (such as thrombocytopaenia) dependent on its present lack of specificity; ${ }^{14}$ its potency and dosage are difficult to assess $;^{15}$ severe local and systemic reactions are frequently encountered in the use of horse antisera; ${ }^{6}$ and, finally, it is thought to be capable of inducing, both at the site of injection ${ }^{7}$ and elsewhere, ${ }^{8}$ tumours of the lymphoid series of cells.

These doubts have resulted in the continuing use of corticosteroids and immunosuppressants such as azathioprine. However, both these preparations ${ }^{9} 10$ have proved much less effective than was initially hoped, ${ }^{11}$ particularly for those forms of nephritis showing extensive formation of periglomerular crescents and for necrotic glomerulitis running a rapidly progressive course. The most severe forms of progressive nephritis associated with systemic lupus erythematosus may also respond poorly or not at all to treatment.

Recently B. Pirofsky and his colleagues ${ }^{12}$ reported favourably on their experiences with goat antithymocyte and antilymphocyte globulin in three cases with severe progressive nephritis unresponsive to large doses of corticosteroids and, in two of the cases, azathioprine in addition. The first patient had a clinical picture typical of Goodpasture's syndrome, with rapid decline of his creatinine clearance to $23 \mathrm{ml}$./min. despite treatment with high doses of prednisolone and azathioprine. Unfortunately immunofluorescent studies on the renal biopsy specimen are not reported and the histology is briefly described as "focal glomerulonephritis." Goat A.L.G. was given for 98 days, with reduction of the prednisolone dosage but maintenance of the azathioprine. The pulmonary lesions resolved completely, and the creatinine clearance rose to over $60 \mathrm{ml} . / \mathrm{min}$., at which level it remained eight months after A.L.G. treatment. The second patient was a young woman with long-standing systemic lupus erythematosus with nephritis. Reduction of prednisone in high dosage resulted in rapid decline in her creatinine clearance to $23 \mathrm{ml} . / \mathrm{min}$., which did not respond to restoration of prednisolone and azathioprine in addition. A.L.G. was given over 147 days, with return of creatinine clearance to $100 \mathrm{ml} . / \mathrm{min}$. and reduction in proteinuria from 22 to $2 \mathrm{~g}$./day. Meanwhile the prednisolone was decreased but the azathioprine continued. Again the improvement was maintained up to $3 \frac{1}{2}$ months after the end of A.L.G. treatment. The third patient also had lupus nephritis, and became anuric despite treatment with dexamethasone. She died, still anuric, after 30 days' treatment with A.L.G.

These results, while encouraging, are difficult to interpret. In the two successfully treated patients azathiopine was continued throughout. The nephritis of Goodpasture's syndrome has been shown to depend in part on circulating antibody to glomerular basement membrane, ${ }^{13}$ while that of systemic lupus erythematosus has been thought to arise principally from circulating complexes containing antibody, complement, and deoxyribose nucleic acid. Pirofsky and his colleagues performed a variety of tests on their patients, showing that ability to produce antibody was intact but cellmediated immune responses were depressed.

The results of their treatment could be interpreted as an indication that the nephritis apparently responding to the A.L.G. was produced or maintained by cell-mediated mechanisms, though the authors do not themselves discuss 